\title{
Pengaruh Penggunaan Video Online YouTube terhadap Kemampuan Keterampilan Klinik Dasar Mahasiswa Kedokteran Terkait Keterampilan Pewarnaan Gram
}

\author{
Utari Hartati Suryani*), Enny Nugraheni*), Zayadi Zainuddin*) \\ *Fakultas Kedokteran dan IImu Kesehatan Universitas Bengkulu \\ e-mail: zay_adi@yahoo.co.id
}

\begin{abstract}
ABSTRAK
Latar Belakang: Teknik dan metode pembelajaran keterampilan klinik pada pendidikan kedokteran semakin kreatif dan inovatif namun pembelajaran keterampilan klinik saat ini membutuhkan waktu dan sumber daya yang tidak sedikit. Institusi pendidikan kedokteran harus membangun laboratorium dengan perlengkapan simulator modern. Peningkatan penggunaan smartphone, tablet, android mungkin merupakan sarana yang baik untuk pembelajaran keterampilan klinik. Multimedia seperti video online YouTube mungkin menjadi sebuah pilihan guna mengatasi kelemahan tersebut.

Tujuan: Membandingkan pembelajaran keterampilan pewarnaan gram yang menggunakan video online dengan metode pembelajaran melalui demonstrasi dan kombinasi keduanya. Metode: Penelitian ekperimental dengan desain randomized control trial dengan post test dan blinded examination. Sampel adalah mahasiswa kedokteran tahap sarjana kedokteran dibagi secara acak untuk kelompok yang menggunakan metode pembelajaran demonstrasi sebagai kelompok kontrol dan kelompok yang menggunakan metode pembelajaran dengan video online serta kombinasi keduanya sebagai kelompok perlakuan. Data dianalisis dengan uji statistik menggunakan program SPSS 13.00.

Hasil: Tidak terdapat perbedaan yang keterampilan pewarnaan Gram yang bermakna antara kelompok demonstrasi langsung dengan video online maupun metode kombinasi. Keterbacaan hasil pewarnaan Gram antara kelompok demonstrasi langsung video online atau metode kombinasi tidak menunjukkan perbedaan bermakna.

Kesimpulan: Metode pembelajaran pewarnaan Gram dengan memanfaatkan video online maupun metode kombinasi memberikan hasil yang sama dengan metode demonstrasi langsung dalam hal penguasaan keterampilan dan kualitas hasil pewarnaan.
\end{abstract}

Kata Kunci: Keterampilan klinik, Video Online YouTube, Pewarnaan Gram

\begin{abstract}
Background: Techniques and methods of clinical skills learning in medical education are more creative and innovative, but in fact it also takes much time and resources. Medical education institutions should establish a laboratory with modern equipment simulator. Increased use of smartphones, tablets, android might be one of means for learning clinical skills. Multimedia such as YouTube online video may be an option to overcome these weaknesses.

Objective:Comparing the gram staining skill learning using online video with a demonstration and learning methods through a combination of both.

Methods: an experimental study design randomized control trial with blinded post test and examination. The sample are medical student that still on medical degree phase were randomly assigned to groups that use the demonstrations as a learning method (control groups)and who use learning methods with online video as well as a combination of both(treatment group). Data were analyzed by statistical tests using SPSS 13:00.

Results: Data revealed that there was no significant differences on Gram staining skills by using online video or combined method in comparison to direct demonstration method.
\end{abstract}


Data also revealed that readability of Gram staining specimens also in the same manner as skills result data.

Conclusion: Application of online video and combined method provided similar result with direct demonstration in terms of skills acquirement and slide quality.

Keywords: Clinical Skill, YouTubeOnline Video, Gram Staining

\section{PENDAHULUAN}

Teknik dan metode

pembelajaran keterampilan klinik pada pendidikan kedokteran semakin kreatif dan inovatif. Salah satu metode pembelajaran yang digunakan secara meluas hingga saat ini adalah demonstrasi menggunakan simulator (Lehmann et al., 2013). Simulator pada pendidikan kedokteran merupakan sebuah revolusi pembelajaran pada praktik keterampilan mahasiswa kedokteran. Pembelajaran menggunakan simulator merupakan salah satu metode pada pendidikan kesehatan yang diupayakan menyerupai pada situasi klinik yang nyata sehingga mampu mentransfer keterampilan yang diperlukan untuk pelayanan kesehatan (Akaike et al., 2012).

Selama beberapa dekade, pusat keterampilan klinik atau lebih dikenal labskill sudah diperkenalkan dengan desain yang spesifik sebagai fasilitas pendidikan untuk mempersiapkan mahasiswa kedokteran melakukan praktik kedokteran yang aman bagi pasien (Duvivier et al., 2009). Semakin banyak juga lab skill pada institusi pendidikan kedokteran yang menyediakan berbagai simulator sebagai perlengkapan untuk pembelajaran keterampilan klinik mahasiswa kedokteran. (Tran et al., 2012)Di sisi lain,penggunaan simulator memerlukan biaya tidak sedikit yang harus disediakan oleh institusi. Sumber daya yang diperlukan dan dilatih untuk menggunakan simulator tersebut juga tidak sedikit. Belum lagi, sering terjadinya kerusakan simulator sehingga memerlukan investasi yang cukup tinggi untuk pemeliharaan. Hal ini juga menjadi alasan lain untuk pembatasan waktu paparan mahasiswa menggunakan simulator tersebut. (Tolsgaard et al., 2013).

Berbagai alasan tersebut diatas maka diperlukan inovasi pendidikan kedokteran lainnya untuk mengajarkan keterampilan klinik pada mahasiswa kedokteran tanpa mengurangi kompetensi yang harus diajarkan pada mahasiswa. Akhir-akhir ini pada berbagai literatur, fokus pengembangan pembelajaran keterampilan klinik pada mahasiswa kedokteran mengarah pada upaya efisiensi dan efektifitas biaya dan sumber daya. Salah satu yang digagas adalah penggunaan multimedia interaktif yang sudah banyak ditemukan pada dunia maya atau online. 


\section{METODE}

Penelitian ekperimental dengan desain randomized control trial dengan post test dan blinded examination yang dilakukan selama 1 (satu) hari di Laboratorium Keterampilan Klinik Dasar(Skills Lab)Fakultas Kedokteran dan IImu Kesehatan Universitas Bengkulu

Pengumpulan data dilakukan dengan beberapa tahapan yaitu:

a. Pencarian dan Penyaringan Video Online YouTube

Video online YouTube terkait dengan keterampilan pewarnaan Gram akan ditelusuri dan dipilih satu per satu sehingga diperoleh video yang dapat dijadikan pembelajaran untuk mahasiswa.

b. Overview mengenai pewarnaan Gram

Seluruh sampel dikumpulkan dalam satu kelas untuk diberikan pengetahuan tentang keterampilan pewarnaan Gram selama 2 jam dengan menggunakan metode kuliah. Semua sampel dipapar dengan materi yang sama.

c. Praktik Keterampilan

Seluruh sampel dibagi secara acak menjadi 3 kelompok. Setiap kelompok langsung mempraktikkan keterampilan keterampilan pewarnaan Gram dengan menggunakan masing-masing melalui metode pembelajaran yang berbeda. Kelompok 1 (satu) sebagai kelompok kontrol belajar menggunakan metode peragaan langsung atau demonstrasi, kelompok 2 (dua) dan 3 (tiga) menggunakan masing-masing metode pembelajaran dengan video online dan kombinasi keduanya sebagai kelompok perlakuan. Setiap kelompok berada di ruangan yang berbeda dan tertutup. Pada tahapan ini, setiap kelompok disediakan waktu selama 2 (dua) jam untuk praktik.

\section{d. Post-test}

Pada tahap ini seluruh sampel kembali memperagakan keterampilan pewarnaan Gram dengan metode yang telah didapatkan dari meted pembelajaran yang telah didapatkan. Hasil dari pewarnaan tersebut akan dilihat secara mikroskopis dan diinterpretasikan hasilnya. Hasil pengecatan digunakan untuk penilaian oleh satu orang ahli yang sama sekali tidak mengenal subjek penelitian (blinded examination).

\section{HASIL}

Pada penelitian ini diperoleh sampel sebanyak 36 orang yang terbagi menjadi 3 kelompok. Kelompok kontrol terdiri dari kelompok yang menggunakan metode pembelajaran dengan demonstrasi langsung sedangkan kelompok perlakuan terdiri dari kelompok yang menggunakan metode pembelajaran dengan video online dan kombinasi keduanya.Semua sampel merupakan mahasiswa kedokteran yang belum sama sekali terpapar praktik keterampilan pewarnaan Gram. 


\begin{abstract}
Ketiga kelompok sampel tersebut dipilih berdasarkan pertimbangan kelompok yang memiliki gaya belajar yang sama yaitu dominan audio dengan rata-rata hasil tes potensi akademik yang hampi sama. Pemilihan sampel tersebut diperlukan untuk menghindari bias yang mungkin terjadi pada penelitian ini. Misalnya sampel yang memiliki gaya belajar kinestetik maka sampel tersebut cenderung mampu belajar memahami melalui praktik langsung dibandingkan sampel yang memiliki gaya belajar audio yang cenderung hanya memahami proses belajar dengan cara melihat. Begitu juga hasil rata-rata potensi akademik yang lebih tinggi maka paling tidak memiliki pemahaman atau kecepatan belajar
\end{abstract}

yang lebih baik dibandingkan sampel yang memiliki rata-rata potensi akademiknya yang rendah.

Penelitian ini dilakukan satu hari dengan berbagai tahapan yaitu tahap pertama adalah penjelasan teknik dasar pewarnaan Gram yang dilaksanakan selama 1 jam. Pada tahap ini, semua sampel dikumpulkan dalam satu ruangan yang sama dan diberikan materi yang sama dengan menggunakan metode kuliah. Tahap kedua, semua sampel langsung melakukan praktikpewarnaan Gram selama 2 jam. Sampel terbagi menjadi 3 kelompok yaitu kelompok yang menggunakan metode demonstrasi langsung, video online dan kombinasi keduanya.

Tabel 1.Perbandingan pewarnaan Gram (gram staining) antara kelompok yang praktik menggunakan metode demonstrasi langsung dan video online

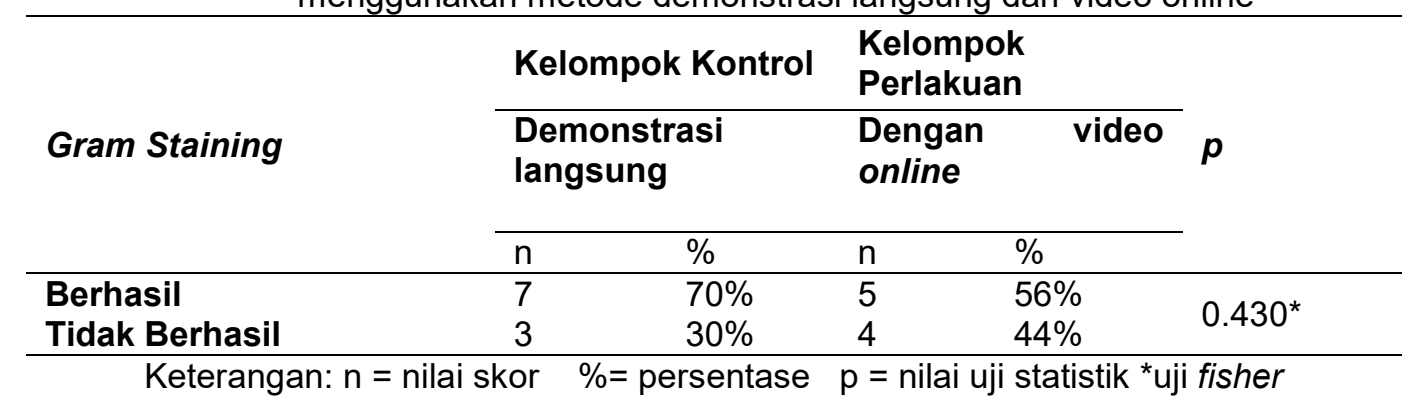

Tabel 2. Perbandingan hasil pewarnaan Gram (gram staining) antara kelompok yang praktik menggunakan metode demonstrasi langsung dan video online

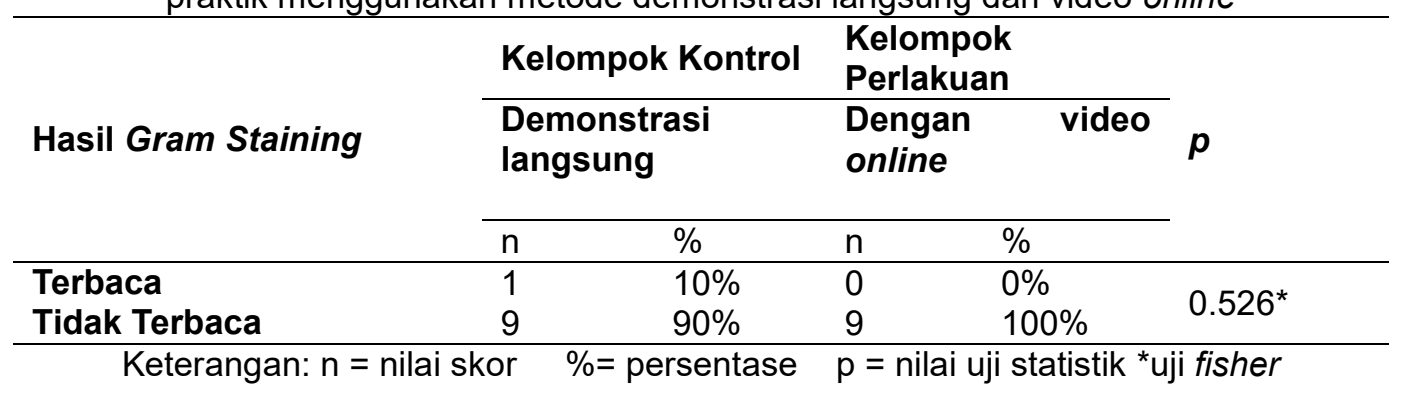


Tabel 3.Perbandingan pewarnaan Gram (gram staining) antara kelompok yang praktik menggunakan metode demonstrasi langsung dan kombinasi

\begin{tabular}{|c|c|c|c|c|c|}
\hline \multirow{3}{*}{ Gram Staining } & \multicolumn{2}{|c|}{$\begin{array}{l}\text { Kelompok } \\
\text { Perlakuan }\end{array}$} & \multicolumn{2}{|c|}{ Kelompok Kontrol } & \multirow{3}{*}{$p$} \\
\hline & & $\begin{array}{l}\text { yang } \\
\text { lakan } \\
\text { ombinasi }\end{array}$ & $\begin{array}{l}\text { Pré } \\
\text { me } \\
\text { de } \\
\text { lan }\end{array}$ & $\begin{array}{l}\text { yang } \\
\text { nakan } \\
\text { trasi } \\
\text { g }\end{array}$ & \\
\hline & $\mathrm{n}$ & $\%$ & $\mathrm{n}$ & $\%$ & \\
\hline $\begin{array}{l}\text { Berhasil } \\
\text { Tidak Berhasil }\end{array}$ & $\begin{array}{l}7 \\
3\end{array}$ & $\begin{array}{l}70 \% \\
30 \%\end{array}$ & $\begin{array}{l}7 \\
3\end{array}$ & $\begin{array}{l}70 \% \\
30 \%\end{array}$ & $0.686^{*}$ \\
\hline
\end{tabular}

Tabel 4.Perbandingan hasil pewarnaan Gram (gram staining) antara kelompok yang praktik menggunakan metode demonstrasi langsung dan kombinasi

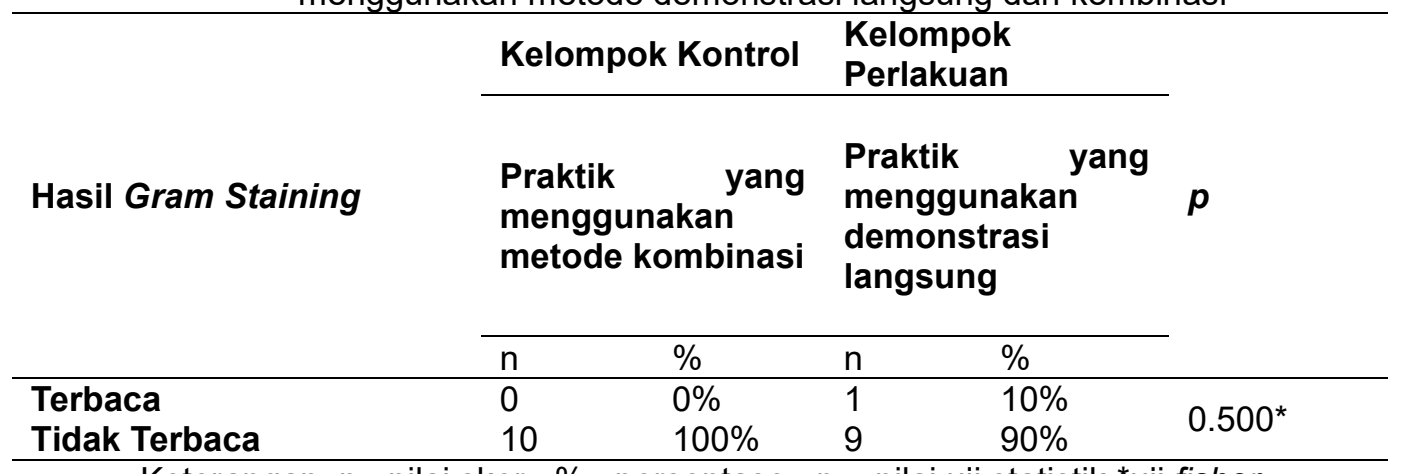

Keterangan: $\mathrm{n}=$ nilai skor $\%=$ persentase $\mathrm{p}=$ nilai uji statistik *uji fisher

Untuk kelompok demonstrasi dan

kombinasi dibimbing oleh masing-masing satu orang tutor sedangkan kelompok yang menggunakan video online tidak didampingi oleh tutor. Sebelumnya, tutor dilakukan pengarahansehingga terdapat kesamaan metode dan pembelajaran dalam membimbing kelompok sesuai dengan video online pewarnaan Gram yang diperoleh. Tahap ketiga, semua sampel dilakukan evaluasi dengan melakukan pewarnaan Gram untuk masing-masing sampel. Hasil dari pewarnaan Gram tersebut akan dilakukan penilaian. Penilaian pada sampel ini dilakukan dengan metode blinded examination yaitu setiap penilai tidak mengetahui sama sekali terhadap sampel yang dinilai sehingga objektifitas dapat terjaga. Tim penilai terdiri dari 2 orang dosen yang menggunakan pedoman atau lembar penilaian yang sama

\section{PEMBAHASAN}

Dari hasil yang didapatkan terlihat bahwa tidak terlihat perbedaan tingkat keberhasilan yang bermakna antara kelompok kontrol yang memperoleh perlakuan praktik setelah melihat demonstrasi langsung dan kelompok perlakuan yang melakukan praktik setelah melihat video tutorial online. Hal ini diperkuat dengan adanya hasil uji statistik yang memiliki nilai 0.430 .

Dari hasil yang didapatkan tidak terlihat perbedaan bermakna dalam tingkat keberhasilan pewarnaan antara kelompok kontrol yang melakukan praktik setelah 
memperhatikan demonstrasi langsung jika dibandingkan dengan kelompok perlakuan yang melakukan praktik pewarnaan setelah melewati proses pembelajaran berupa tutorial dengan demonstrasi langsung dan juga menonton video online (melewati 2 proses perlakuan)

Dari hasil yang didapatkan tidak terlihat perbedaan bermakna terhadap hasil pewarnaan yang dapat terbaca/tidak terbaca antara kelompok kontrol yang melakukan praktik setelah melihat tutorial dengan metode demonstrasi langsung dengan kelompok yang melakukan praktik setelah mendapatkan tutorial dengan 2 metode (menyaksikan demonstrasi langsung dan menonton video online).

Masih banyaknya kekurangan yang terjadi dalam proses penelitian ini memberikan beberapa efek, salah satunya terlihat dari hasil yang didapatkan, dimana tidak terlihat perbedaan yang bermakna akan hasil yang didapatkan dari masing-masing kelompok perlakuan. Hal ini mungkin saja disebabkan oleh beberapa faktor dengan jumlah populasi sampel yang kurang banyak sehingga hasil yang didapatkan dirasa masih kurang representatif. Meskipun jumlah total populasi yang melakukan proses pengecatan ini seluruhnya ada sekitar 80 orang, namun yang dapat memenuhi kriteria sampel hanya 29 orang.

Di sisi lainnya keterbatasan alat dan bahan yang dimiliki juga menjadi salah satu faktor penentu, dimana sediaan isolat yang terbatas dan kondisinya yang sudah tidak terlalu baik juga ikut mempengaruhi hasil pewarnaan yang didapatkan. Selain itu kesamaan alat dan bahan peraga yang benarbenar sama dalam proses pembelajaran juga perlu diperhatikan. Hal ini perlu diperbaiki sehingga di kemudian hari dapat dilakukan penelitian lanjutan yang lebih baik dengan persiapan yang juga tentunya lebih baik.

\section{KESIMPULAN}

Metode pembelajaran pewarnaan Gram dengan memanfaatkan video online maupun metode kombinasi memberikan hasil yang sama dengan metode demonstrasi langsung dalam hal penguasaan keterampilan dan kualitas hasil pewarnaan.

\section{DAFTAR PUSTAKA}

Azer, S.A., 2014. Understanding pharmacokinetics: are YouTube videos a useful learning resource? Eur. Rev. Med. Pharmacol. Sci. 18, 1957-1967.

Azer, S.A., AlGrain, H.A., AlKhelaif, R.A., AlEshaiwi, S.M., 2013. Evaluation of the Educational Value of YouTube Videos About Physical Examination of the Cardiovascular and Respiratory Systems. J. Med. Internet Res. 15. doi:10.2196/jmir.2728

Duvivier, R.J., Van Dalen, J., Van Der Vleuten, C.P.M., Scherpbier, A.J.J.A., 2009. Teacher perceptions of desired qualities, competencies and strategies for clinical skills teachers. Med. Teach. 31 , 634-641. doi:10.1080/01421590802578228

Jang, H.W., Kim, K.-J., 2014. Use of online clinical videos for clinical skills training for medical students: benefits and challenges. BMC Med. Educ. 14, 56.

Lehmann, R., Bosse, H.M., Simon, A., Nikendei, C., Huwendiek, S., 2013. An innovative blended learning approach using virtual patients as preparation 
for skills laboratory training: Vivekananda-Schmidt, P., Lewis, M., Coady,

perceptions of students and tutors.

BMC Med. Educ. 13, 23.

Tran, T.Q., Scherpbier, A., Van Dalen, J., Wright, P.E., 2012. Teacher-made models: the answer for medical skills training in developing countries? BMC Med. Educ. 12, 98.
D., Morley, C., Kay, L., Walker, D., Hassell, A.B., 2007. Exploring the use of videotaped objective structured clinical examination in the assessment of joint examination skills of medical students. Arthritis Care Res. 57, 869-876. doi:10.1002/art.22763 